\title{
Research of throttled interchamber cross-flow in multifuel engine
}

\author{
Dmitriy Mikhailovich Vokhmin \\ Industrial University of Tyumen \\ 625000, Ural Federal District, Tyumen region, \\ Tyumen, Volodarskogo St., 38 \\ wokhmin@gmail.com
}

\begin{abstract}
The article discusses the analysis of the influence of the connecting hole diameter on the amount of the mixture, flowing from the basic volume to the additional volume at the compression stroke in the prechamber engine. The resulting mathematical model allows one to accurately determine the amount of fresh charge, overflowing from the main combustion chamber into the secondary chamber at the compression stroke. The quantity of overflowing charge, taking into account the presence of throttling, allows one to determine the composition of the air-fuel mixture in the main and additional combustion chambers. Owing to the obtained results, it becomes possible to select the optimum mixture composition by adjusting the amount of fuel supplied. The experimental data on the immunity of the thermodynamic cycle of the upgraded engine to different sorts of fuels within a wide range of octane numbers and their viscosity by optimizing the air coefficient in the additional chamber without departing from the optimum ignition limits in all load conditions are given.
\end{abstract}

Keywords - prechamber; antechamber; throttling section; multi-fuel engine; excess air coefficient; thermodynamic cycle

\section{INTRODUCTION}

One of the indisputable advantages of the separated combustion chambers is a larger predisposition to multifuel capability, compared to the opened ones, since they exhibit less rigidity of combustion process behavior, which can be further reduced by introducing into the construction of the combustion chamber, arranged in the head (or more rarely in the engine block) of active combustion management elements - insulated inserts cylinders, the temperature of which can be maintained at a high level (up to $972 \mathrm{~K}$ or more), allowing to significantly reduce the duration of the ignition delay period.

The further development of double-volume engines is the introduction of elements of active management of the processes of mixing and combustion such as a forced ignition system [1] and the use of a shaped nozzle. The methods of such prechamber geometry design are described in detail in the article [2].

The problem, the solution of which would solve the uncertainty of repeatability in successive ignition cycles, is determining the composition of the mixture at the moment of ignition at different speed modes of engine operation [3-4].

The problem lies in the uncertainty of the amount of air overflowing from the main combustion chamber in the additional involving throttling.
The value of throttling is determined by the diameter of the connecting channel between the main and additional chambers.

Along with the change in the amount of air, throttling entails a pressure differential between the chambers and, under its significant value, causes a reduction in the degree of compression in the additional volume.

At the same time, moderate throttling increases the energy parameters of the secondary camera on the back overflowing during the combustion process.

These studies are aimed at solving the whole complex of uncertainties and assumptions in the process of designing such systems.

\section{METHODS}

Determination of the prechamber charge at throttled interchamber cross-flow

During compression in the double chamber internal combustion engine, a redistribution of the charge mass balance between the chamber volumes takes place. This redistribution occurs as a result of the overflowing of a part of the charge from the basic volume to the antechamber volume [5].

The mixture composition in the additional volume will depend on timings of the fuel supply and ignition.

Equations which reflect a change in the mixture composition in the course of the overflowing can be obtained by developing the known factors of thermodynamics and compression process in a two-chamber engine with respect to an arbitrary point of indicator diagram in the course of injection on compression branches [6] of the transform of special case, reflecting a change in the mixture composition in the additional chamber at non-throttled overflowing.

$$
\Delta G_{x}=\frac{a}{\varepsilon} \cdot\left[\frac{\varepsilon}{(\varepsilon-1) \cdot f(\delta)+1}-1\right] \cdot G_{\Sigma} .
$$

The disadvantage of formula (1) is the absence of its universality since it involves the alignment of the pressure in the main and additional chambers at the intermediate points of the compression stroke. Therefore, this formula is of little use 
in determining the prechamber charge at throttled overflowing when at the end of the compression stroke, $\mathrm{P}_{\mathrm{c}}>\mathrm{P}_{\mathrm{c}}$ '.

A method for determining the number of overflowed prechamber charge, which takes into account the pressure inequality in primary and additional chambers, is provided below.

To determine the amount of the mixture, overflowing into the antechamber volume, let us consider the differential equation, determining the state of the gas in its volume under an infinitesimal movement of the piston.

Considering that $\mathrm{V}_{\mathrm{k}}=$ const:

$$
V_{k} \cdot d P=R T d G+G R d T
$$

The termwise division of the equation by the characteristic equation:

$$
P V_{k}=G R T
$$

gives

$$
\frac{d P}{P}=\frac{d G}{G}+\frac{d T}{T}
$$

Under adiabatic compression process flow, for arbitrary point $x$, there is the following equation:

$$
T_{x}=T_{a} \cdot\left(\frac{P_{x}}{P_{a}}\right)^{\frac{k-1}{k}},
$$

where $\mathrm{k}$ is the adiabatic index.

Using the relation between temperature and pressure, one can write:

$$
d T=\frac{k-1}{k} \cdot \frac{T_{a}}{P_{a}^{\frac{k-1}{k}} \cdot P_{x}^{\frac{1}{k}}} \cdot d P
$$

Substituting (4) and (5) into equation (3) leads to the form:

$$
\frac{d P}{P}=\frac{d G}{G}+\frac{k-1}{k} \cdot \frac{d P}{P}
$$

from which

$$
\frac{1}{k P} \cdot d P=\frac{d G}{G}
$$

$$
\frac{d P}{P}=k \cdot \frac{d G}{G}
$$

Integrating term by term the right and left side of the equation (9)

$$
\int_{a}^{x} \frac{d P}{P}=k \cdot \int_{a}^{k} \frac{d G}{G},
$$

one obtains

$$
\lg P_{x}=k \cdot \lg G_{x}+C,
$$

or it can be represented as

$$
P_{x}=C \cdot G_{x}^{k}
$$

The constant of integration is found from the condition that at the beginning, $\mathrm{P}=\mathrm{P}_{a}$ and $\mathrm{G}=\mathrm{G}_{1 a}$, where $\mathrm{G}_{1 a}$ - weight quantity of the charge at the beginning of compression in the prechamber:

$$
C=\frac{P_{a}}{G_{1 a}^{k}} .
$$

For any moment of the compression process in the prechamber:

$$
P_{x}=\left(\frac{G_{x}}{G_{1 a}}\right)^{k},
$$

or given that for the antechamber

$$
G_{x}=G_{1 a}+\Delta G_{x},
$$

then

$$
P_{x}=P_{a} \cdot\left(1+\frac{\Delta G_{x}}{G_{1 a}}\right)^{k} .
$$

Expression (6) can be written as:

$$
P_{x}^{\frac{1}{k}}=P_{a}^{\frac{1}{k}} \cdot\left(1+\frac{\Delta G}{G_{1 a}}\right),
$$

or 


$$
G_{1 a} \cdot P_{x}^{\frac{1}{k}}=P_{a}^{\frac{1}{k}} \cdot G_{1 a}+P_{a}^{\frac{1}{k}} \cdot \Delta G_{x}
$$

For the charge, overflowed into the prechamber cavity at an arbitrary point at the compression stroke, one has:

$$
\Delta G_{x}=\frac{G_{1 a}\left(P_{x}^{\frac{1}{k}}-P_{a}^{\frac{1}{k}}\right)}{P_{a}^{\frac{1}{k}}}
$$

given that

$$
P_{x}^{\frac{1}{k}}=P_{a} \cdot\left(\frac{P_{a}^{\frac{1}{k}} \cdot \varepsilon_{x}-P_{x}^{\prime \frac{1}{k}} \cdot a}{P_{a}^{\frac{1}{k}}(1-a)}\right),
$$

one obtains

$$
\Delta G_{x}=G_{1 a} \cdot\left[\left(\frac{P_{a}^{\frac{1}{k}} \cdot \varepsilon_{x}-P_{x}^{\prime \frac{1}{k}} \cdot a}{P_{a}^{\frac{1}{k}}(1-a)}\right)-1\right] .
$$

In equation (21), $\frac{P_{a}^{\frac{1}{k}} \cdot \varepsilon_{x}-P_{x}^{\prime \frac{1}{k}} \cdot a}{P_{a}^{\frac{1}{k}}(1-a)}$ is the current value of the degree of compression which takes into account the presence of throttling and is determined by the position of the piston at point $x$ of the indicator diagram.

The geometric parameters are shown in Fig. 1.

$$
\frac{P_{a}^{\frac{1}{k}} \cdot \varepsilon_{x}-P_{x}^{\frac{1}{k}} \cdot a}{P_{a}^{\frac{1}{k}}(1-a)}=\frac{P_{x}^{\frac{1}{k}}}{P_{a}^{\frac{1}{k}}}=\left(\frac{P_{x}}{P_{a}}\right)^{\frac{1}{k}}=\frac{V_{a}}{V_{x}}=f\left(\varepsilon_{x}\right) .
$$

The value of this relation can be obtained from the adiabatic equation for an arbitrary point $x$ :

$$
P_{x} \cdot V_{x}^{k}=P_{a} \cdot V_{a}^{k}
$$

from which

$$
\left(\frac{P_{x}}{P_{a}}\right)^{\frac{1}{k}}=\frac{V_{a}}{V_{x}}=\frac{P_{a}^{\frac{1}{k}} \cdot \varepsilon_{x}-P_{x}^{\frac{1}{k}} \cdot a}{P_{a}^{\frac{1}{k}} \cdot(1-a)}=f\left(\varepsilon_{x}\right) .
$$

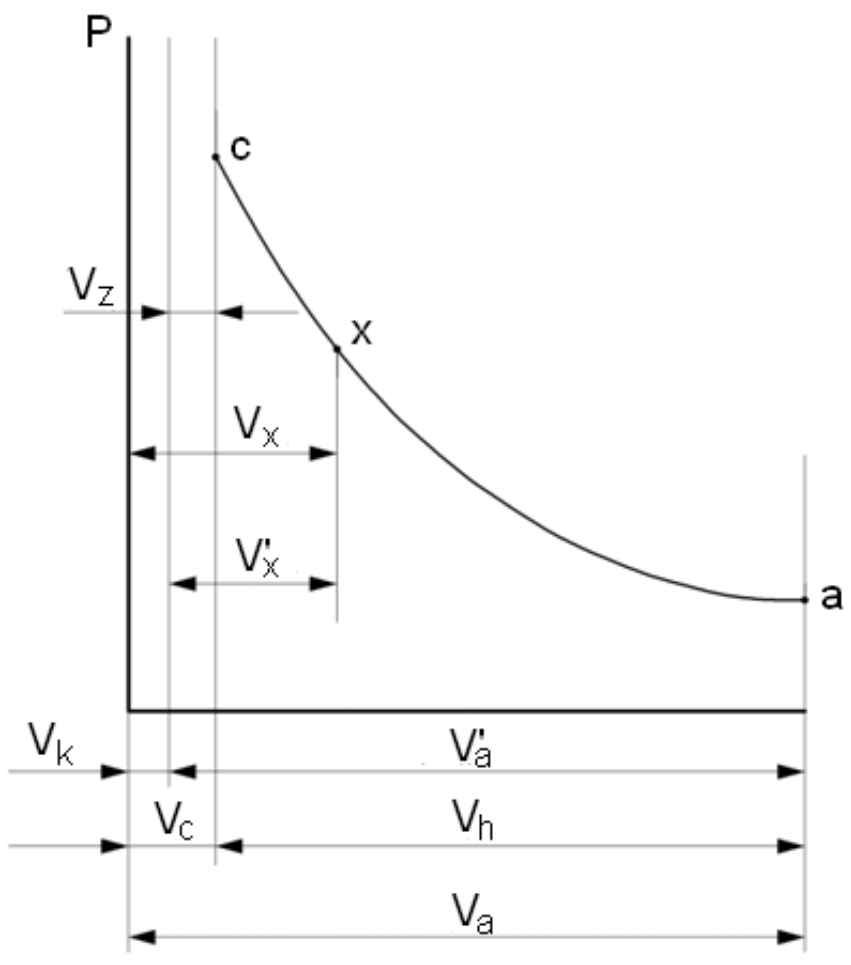

Fig. 1. Distribution of the volume at the compression stroke.

The value of $V_{x}$ is the sum of the volumes consisting of a volume left for the piston to pass from point $x$ to the top dead center and compression space volume $\mathrm{V}_{\mathrm{c}}$ :

$$
V_{x}=V_{c}+V_{h} \cdot \frac{1}{2} \cdot\left(1-\cos \delta+\frac{1}{2} \cdot \lambda \cdot \sin ^{2} \delta\right),
$$

or in an abbreviated form

$$
V_{x}=V_{c}+V_{h} \cdot f(\delta),
$$

or

$$
V_{x}=\frac{V_{a}}{f\left(\varepsilon_{x}\right)}+V_{h} \cdot f(\delta),
$$

where: 
$f(\delta)=\frac{1}{2} \cdot\left(1-\cos \delta+\frac{1}{2} \cdot \lambda \cdot \sin ^{2} \delta\right)$

$\lambda=\frac{r}{l}$

$r$ - crankshaft radius;

$l$ - piston rod length;

Angle $\delta$ corresponds to the position of the piston at point $x$.

Substituting these equations (26) into equation (20), one obtains:

$$
f\left(\varepsilon_{x}\right)=\frac{f\left(\varepsilon_{x}\right)}{\left(f\left(\varepsilon_{x}\right)-1\right) \cdot f(\delta)+1},
$$

and after substituting the resulting expression into (21), there is:

$$
\Delta G_{x}=G_{1 a} \cdot\left[\frac{f\left(\varepsilon_{x}\right)}{\left(f\left(\varepsilon_{x}\right)-1\right) \cdot f(\delta)+1}-1\right] .
$$

Value $\mathrm{G}_{l a}$ can be obtained from the known [7] expression

$$
G_{v, c}=\frac{2}{\pi} \cdot \varphi \cdot S_{2} \cdot \sqrt{\frac{j}{2 \tau} \cdot 2 g \cdot \gamma_{v} \cdot \Delta P}
$$

where $\mathrm{j}-$ the number of cylinders of the engine; $\tau=2-$ in a four-stroke; $\tau=1$ - in a two-stroke.

$$
G_{1 a}=G_{\Sigma}-G_{2 a}=\frac{a}{f\left(\varepsilon_{x}\right)} \cdot G_{\Sigma},
$$

after substituting, expression (29) gives

$$
\Delta G_{x}=\frac{a}{f\left(\varepsilon_{x}\right)} \cdot\left[\frac{f\left(\varepsilon_{x}\right)}{\left(f\left(\varepsilon_{x}\right)-1\right) \cdot f(\delta)+1}-1\right] \cdot G_{\Sigma}
$$

This equation allows us to calculate the weight fraction of the total combustible mixture quantity overflowed from the cylinder volume into prechamber volume $\mathrm{V}_{\mathrm{k}}$ during the compression process.

With some approximation, it can be assumed that the amount of air $\Delta \mathrm{G}_{\mathrm{v}, \mathrm{c}}$ in the combustible mixture, overflowed to the prechamber, will be proportional to its charge quantity $\Delta \mathrm{G}_{\mathrm{x}}$

Table 1 lists the values of these coefficients for known connecting channel diameters and volumes of the prechamber, and the pressure ratio increase in the main volume and for an equivalent increase of the compression ratio.
Knowing the flow rate per hour of the air, flowed into the cylinder, one can determine the weight of the air, overflowed to the prechamber:

$$
\Delta G_{v, x}=\frac{G_{v, c} \cdot \Delta G_{x}}{G_{\Sigma}}
$$

substituting and transforming the value of $\Delta \mathrm{G}_{\mathrm{x}}$ from (31), one

\begin{tabular}{|c|c|c|c|c|}
\hline \multirow[b]{2}{*}{$\begin{array}{c}\text { Relative } \\
\text { volume of the } \\
\text { additional } \\
\text { chamber } \\
a=V_{k} / V_{c} \\
\text { when } \\
\mathbf{n}=2000 \text { min }^{-1}\end{array}$} & \multicolumn{4}{|c|}{ Indicators } \\
\hline & $\begin{array}{c}\text { The } \\
\text { smallest } \\
\text { diameter } \\
\text { of } \\
\text { connecting } \\
\text { channel } \\
d_{\mathrm{kr}}, \mathrm{mm}\end{array}$ & $\begin{array}{c}\text { Pressure } \\
\text { drop } \\
\Delta \mathrm{P} \mathrm{MPa}\end{array}$ & $\begin{array}{c}\text { Value of the } \\
\text { decrease in } \\
\text { the degree } \\
\text { of } \\
\text { compression } \\
\text { in } \\
\text { prechamber } \\
\Delta \varepsilon\end{array}$ & $\begin{array}{c}\text { Coefficient } \\
\text { influencing } \\
\text { the } \\
\text { increase in } \\
\text { pressure in } \\
\text { main } \\
\text { chamber B }\end{array}$ \\
\hline \multirow{5}{*}{0.1} & 2 & 0.065 & 0.6 & 0.925 \\
\hline & 3 & 0.021 & 0.2 & 0.975 \\
\hline & 4 & 0.007 & 0.05 & 0.993 \\
\hline & 5 & 0 & 0 & 1 \\
\hline & 6 & 0 & 0 & 1 \\
\hline \multirow{5}{*}{0.2} & 2 & 0.15 & 1 & 0.875 \\
\hline & 3 & 0.075 & 0.5 & 0.973 \\
\hline & 4 & 0.028 & 0.1 & 0.987 \\
\hline & 5 & 0.009 & 0.03 & 0.996 \\
\hline & 6 & 0 & 0 & 1 \\
\hline \multirow{5}{*}{0.3} & 2 & 0.35 & 2.5 & 0.688 \\
\hline & 3 & 0.188 & 1.1 & 0.863 \\
\hline & 4 & 0.1 & 0.6 & 0.925 \\
\hline & 5 & 0.035 & 0.2 & 0.975 \\
\hline & 6 & 0.01 & 0.08 & 0.998 \\
\hline
\end{tabular}
obtains:

$$
\Delta G_{x}=G_{v} \cdot \frac{a}{f\left(\varepsilon_{x}\right)} \cdot\left[\frac{f\left(\varepsilon_{x}\right)}{\left(f\left(\varepsilon_{x}\right)-1\right) \cdot f(\delta)+1}-1\right]
$$

TABLE I. INFLUENCE OF $a$ AND $d_{k}$ ON THE PRESSURE INCREASE IN THE MAIN COMBUSTION CHAMBER

In a simplified form, formula (34) takes the form of:

$$
\Delta G_{x}=\frac{a}{B \cdot \varepsilon_{x}} \cdot\left[\frac{B \cdot \varepsilon_{x}}{\left(B \cdot \varepsilon_{x}-1\right) \cdot f(\delta)+1}-1\right] \cdot G_{\Sigma},
$$

where:

$\varepsilon_{x}$ - is the current value of the compression ratio;

$\mathrm{B}$ - is the coefficient affecting the increase in pressure in the main combustion chamber with known throttling parameters.

The diagram in Figure 2 shows the calculated values of the amount of air, overflowed into the prechamber in the interval from $40^{\circ}$ of the crankshaft rotation at the compression stroke to the top dead center at $1800 \mathrm{~min}^{-1}, \varepsilon=6.4 ; a=0.3$. 


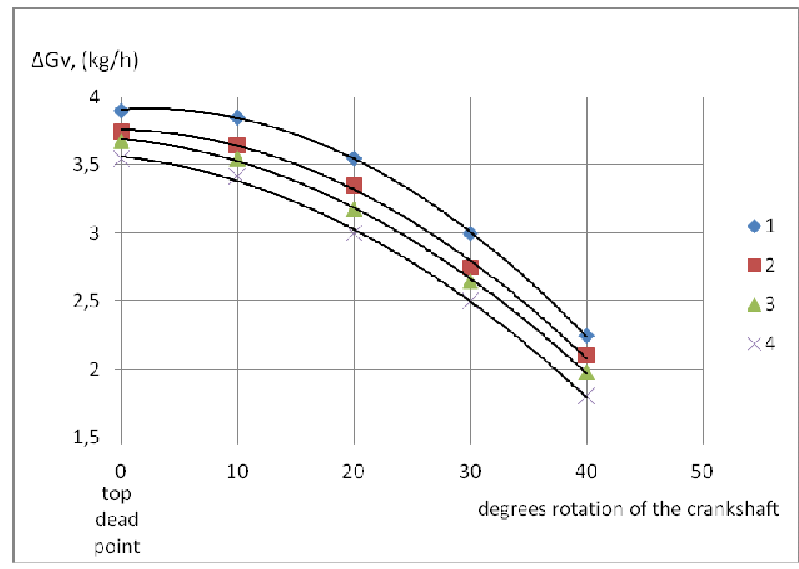

Fig. 2. The regularity of the changes of prechamber charge. $(1-$ no throttling, 2 - throttling $\mathrm{d}_{\mathrm{kr}}=5 \mathrm{~mm}, 3-$ throttling $\mathrm{d}_{\mathrm{kr}}=4 \mathrm{~mm}, 4-$ throttling $\mathrm{d}_{\mathrm{kr}}$ $=3 \mathrm{~mm}$ )

\section{RESULTS}

The experimental studies are conducted in order to obtain factual data to identify some trends and patterns of operation of the engine according to the developed scheme.

As for the object of the whole study, a single-cylinder four-cycle engine UD-15 was taken, the characteristics of which are presented in Table 2.

TABLE II. ENGINE DATA

\begin{tabular}{|c|c|}
\hline Parameter & Value \\
\hline Number of cylinders & 1 \\
\hline Number of cycles & 4 \\
\hline Frequency of crankshaft rotation & $3000 \mathrm{~min}^{-1}$ \\
\hline Bore diameter & $72 \mathrm{~mm}$ \\
\hline Stroke of piston & $60 \mathrm{~mm}$ \\
\hline $\begin{array}{c}\text { The initial degree of compression in the } \\
\text { single-chamber engine }\end{array}$ & 6 \\
\hline Useful capacity & $245 \mathrm{~cm}^{3}$ \\
\hline Cooling & by air \\
\hline
\end{tabular}

- The head of the batch production engine cylinder has undergone a rework to raise the degree of compression. Its volume has been reduced from $50 \mathrm{~cm}^{3}$ to $35 \mathrm{~cm}^{3}$, which made it possible to increase the degree of compression to $\varepsilon=8$.

- The experiments were performed on a modified head with an attached add-on chamber, the volume of which varied from $a=0.3$ to $a=0.15$ of the cylinder head volume. The degree of compression has changed at that from 6.3 to 6.8 , respectively.

- The engine is equipped with a high pressure fuel pump, driven by the drive gear through the shaft driving a magneto. The fuel injection equipment fits a high pressure single-plunger pump with the diameter of 7 mm.
The workflow scheme being studied is supposed to combine the advantages of the injection in the additional chamber with the merits of the prechamber ignition system. Improved economic performance in this case is expected to be obtained due to the intensification of the air-fuel mixture combustion as a result of the charge ignition in the main chamber not by a point ignition source, but through a flame of hot gases, emerging at a high speed from the secondary chamber.

Such inflammation creates additional turbulence vortices in the air-fuel mixture at the second combustion stage, thereby enabling a nondetonating combustion at higher degrees of compression and eliminating the difference between the physical and chemical properties of various fuels.

When choosing the volume of the additional chamber, it was taken into account that its increase entails:

- Increasing the energy of the torch which to a certain extent is beneficial to the process of ignition and combustion of the mixture in the main combustion chamber volume.

- Reduction of the residual gas coefficient in the prechamber by the beginning of the charge ignition in it.

- Increase in the area of the combustion chamber which leads to an increase in heat losses.

- Deterioration of the engine cylinder filling with fresh charge.

- Increase in heat consumption because of air-fuel mixture overflowing from main cylinder volume to the prechamber at the compression stroke and backflow of the gas at the exhaust stroke.

- Increase in the time of fire coverage of the additional chamber that can negatively affect the dynamics of the combustion process.

The reduced volume of the additional chamber is beneficial to a certain value. An excessive reduction causes a significant increase in specific fuel consumption. In addition, a decrease in the volume of the chamber reduces the power value. This leads to the fact that changes in the mixture composition of the cylinder charge mixture have a stronger effect on an additional chamber performance.

One of the research objectives was finding ways to increase the use of fuel resources. The experiments have shown the possibility of using a variety of fuels such as petrol with octane number up to 80 ; diesel fuel and aviation kerosene which were analyzed during the comparative experiments.

The results give reason to state that the engine, in spite of the non-optimal degree of compression and filling data, acquired a predicted multifuel capability and operates satisfactorily using the named grades of fuel [8-10]. The diagram in Fig. 3 shows it in full. When using petrol, up to 5\% of motor oil was added to it to prevent wear of the high pressure fuel pump plunger. 
The increase in specific fuel consumption when using petrol can be attributed to its lower density and, as a consequence, to an increase in in-piston leaks.

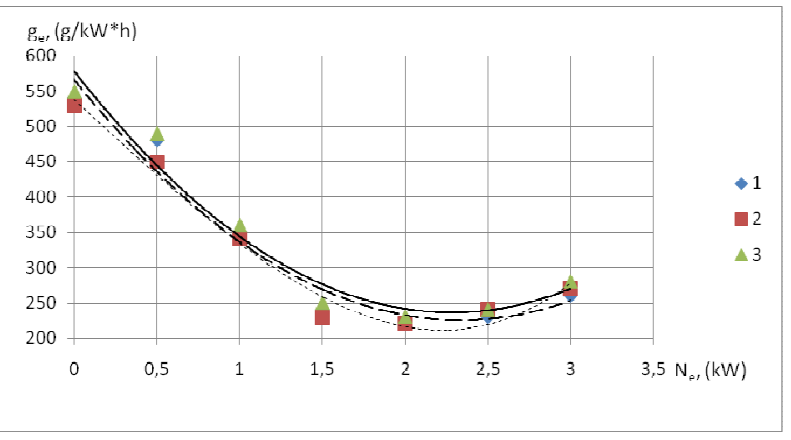

Fig. 3. Comparative characteristics of load $\mathrm{n}=1600 \mathrm{~min}^{-1}$. $(1-$ aviation kerosene, 2 - petrol with an octane number of 80,3 - diesel).

A generalization of experimental data, as well as the given comparison, allows one to state that, when injected into a channel connecting the main and additional combustion chambers and by the cyclic dosage separation during mixingcombustion, the engine gains a tendency to automatic operation using an optimal mixture composition for the given mode.

The optimum composition of the mixture, as well as the determined or conditioned efficiency, depends on the engine heat status.

It should also be noted that the engine operation using optimal mixture composition modes can be achieved using the advantages of torch ignition coupled with the high-quality power adjustment method.

As can be seen from the above-mentioned information, the conduct of the process according to the described scheme allows for the principle of quality power control. At that, changing the mixture quality is achieved by changing the quantity of fuel supply.

\section{CONCLUSION}

- The mathematical model for determining the quantity of the air charge at throttled interchamber cross-flow allows one to take into account more accurately the amount of charge, overflowed to the prechamber chamber, which together with the definition of fuel delivery optimal law, allows one to identify the most favorable for ignition (defined in $\alpha$ ) a compression branch section, as well as to adjust this figure by the active control elements within optimal values.

- A smaller coefficient of residual gases during the compression filling contributes to a higher total filling of the cylinder.

- The studied scheme of the process behaviour by injection into the connecting channel and the use of the cross-flow energy to separate the cyclic dosage in processes of mixing-combustion allows the power control of the engine, by changing the mixture quality from idle run to full power, to increase the degree of compression to the optimum value from the thermodynamic point of view.

- Due to the above-mentioned factors, the engine gains a tendency to automatic operation using mixture compositions, ensuring optimal efficiency at the given loading mode without the need for a mixture quality control system. This fact significantly simplifies the control system during fuel injection.

- The studied design scheme offers the potential use of different grades of fuel, both commercial and unconditioned ones.

- The selected design parameters of the antechamber, nozzle and connecting channel cross-section ensure the stable operation of the engine in the entire range of its speed modes.

\section{References}

[1] D.M. Vokhmin, D.G. Malanichev. "A method of operating an internal combustion engine and the multifuel internal combustion engine", Patent RU 2167316, 2006.

[2] D.M. Vokhmin. "Optimization of mixing energy in two-chamber engines", Research Journal of Pharmaceutical, Biological and Chemical Sciences, 7(5), pp. 928-938, 2016

[3] M.N. Nabi, M.S. Akhter, M.A. Rahman, "Waste transformer oil as an alternative fuel for diesel engine", [In 5th BSME International Conference on Thermal Engineering, pp. 401-406,.K. Elissa, 2013].

[4] A. Rahman, A. Bhanu, "Performance \& analysis of pungamia oil blends with diesel by using single cylinder diesel engine", International Journal of Research in Mechanical Engineering, 1(1), pp. 26-30, 2014.

[5] L. Labecki, A. Cairns, J. Xia, A. Megaritis, H.L. Zhao, L.C. Ganippa, "Combustion and emission of rapeseed oil blends in diesel engine", Appl. Energy 3, pp. 139-146. 2012.

[6] J. Żurek, A. Jankowski, "Experimental and numerical modelling of combustion process of liquid fuels under laminar conditions", Journal of KONES, 21(3), pp.309-316. 2014

7] L. Labecki, A. Cairns, J. Xia, A. Megaritis, H.L. Zhao, L.C. Ganippa, "Combustion and emission of rapeseed oil blends in diesel engine", Appl. Energy ,3 pp. 139-146, 2012.

[8] S. Saravanan, G. Nagarajan, G. Lakshmi Narayana Rao, S. Sampath, "Combustion characteristics of a stationary diesel engine fuelled with a blend of crude rice bran oil methyl ester and diesel", Energy 35, pp. 94 $100,2010$.

[9] L. Labecki, A. Cairns, J. Xia, A. Megaritis, H.L. Zhao, L.C. Ganippa, "Combustion and emission of rapeseed oil blends in diesel engine", Appl. Energy 3, pp. 139-146, 2012.

[10] S. Saravanan, G. Nagarajan, G. Lakshmi Narayana Rao, S. Sampath, "Combustion characteristics of a stationary diesel engine fuelled with a blend of crude rice bran oil methyl ester and diesel", Energy 35, pp. 94 $100,2010$. 